University of Montana

ScholarWorks at University of Montana

$1-1984$

\title{
The Displacement Process in Recreation
}

Dorothy H. Anderson

USDA Forest Service, North Central Forest Experiment Station

Perry J. Brown

University of Montana - Missoula, perry.brown@umontana.edu

Follow this and additional works at: https://scholarworks.umt.edu/forest_pubs

Part of the Forest Management Commons

Let us know how access to this document benefits you.

\section{Recommended Citation}

Anderson, Dorothy H. and Brown, Perry J., "The Displacement Process in Recreation" (1984). Forest Management Faculty Publications. 34.

https://scholarworks.umt.edu/forest_pubs/34

This Article is brought to you for free and open access by the Forest Management at ScholarWorks at University of Montana. It has been accepted for inclusion in Forest Management Faculty Publications by an authorized administrator of ScholarWorks at University of Montana. For more information, please contact scholarworks@mso.umt.edu. 


\title{
The Displacement Process in Recreation
}

\author{
Dorothy H. Anderson and Perry J. Brown
}

\begin{abstract}
This paper presents the recreation displacement process from a social-psychological perspective and models it within the attitudebehavior framework. The displacement process is illustrated with empirical results from a study of use within the Boundary Waters Canoe Area Wilderness. Findings show that factors of displacement include litter, noise, overuse, and visual encounters with others. In most cases, recreation resource administrators should be able to managerially control displacing factors.

KEYWORDS: Displacement, attitude-behavior, Boundary Waters Canoe Area Wilderness, change, use patterns.

AUTHORS: Dorothy H. Anderson is Research Social Scientist, North Central Forest Experiment Station, St. Paul; Perry J. Brown is Professor and Head Department of Resource Recreation Management, Oregon State University, Corvallis.

Journal of Leisure Research, 1984 Volume 16, Number 1, pp. 61-73. Copyright ${ }^{\circ} 1984$ by the National Recreation and Park Association.
\end{abstract}

Federal recreation resource managers are charged with providing opportunities for quality recreation experiences. Despite managers' efforts toward this objective, though, user complaints about resource deterioration, overcrowding and conflicts between users with different recreation goals persist (Driver and Bassett 1975; Anderson 1980). As the number and kinds of users continue to increase, we expect user complaints and conflicts to continue and the manager's job to become increasingly difficult. Consequently, displacement, which suggests something less than a quality experience is obtained by certain users, will become a concern of managers.

Our purposes in this paper are 1) to conceptualize the displacement process in recreation and 2) to illustrate that process with empirical results from a study of use within the Boundary Waters Canoe Area Wilderness. Because recreation research on displacement is new, we have included a definition and brief overview of past research to give the reader relevant background information.

Displacement in recreation is defined as the outcome of a decision to change behavior and is caused by adverse changes in the recreation environment (Anderson 1980). The antecedents for behavior changes are likely to be increased numbers of users that bring about increased social pressures or com- 
petition for space; changes in the physical makeup of the recreation environment; and, changes in the management direction for an area. We wish to consider the displacement process from a social psychological perspective and model it within an attitude-behavior framework. Further, we want to consider if crowding plays a major role in the displacement process. This strategy for studying displacement seems justified for two reasons.

First, behavior and intended behavior have been linked empirically to an individual's attitudes toward attributes in the environment (Zimbardo et al. 1977; Willis et al. 1978; Ajzen and Fishbein 1980). Thus, establishing a link between attitudes and behavior is the first step in understanding the process of displacement. Although the evidence sometimes contradicts the attitudebehavior relation (Wicker 1969), the contradictions probably arise because of inadequate methods (Janeksela 1978).

Second, low quality user experiences are often cited as an effect of increased numbers and kinds of users in wilderness (or wilderness-like) recreation areas (Washburne 1981). Individual differences, setting characteristics, and social conditions influence how users are perceived by and perceive other users in the recreation environment (Bell et al. 1978). In settings where individuals feel they have a high degree of control over other users' and their own actions, crowding is less of a problem and its negative effects are fewer (Langer and Saegert 1977). Recreation areas may represent places where individuals believe they have a high degree of control. Users do not report crowding as limiting recreation behavior as often as might be expected (Smith et al. in press). On the other hand, if excessive numbers of users lead to a perceived decrease in personal freedom and a perceived scarcity of available recreation resources, a feeling of crowding may result (Cohen et al.; Stokols 1972a, $1972 b)$ and it may lead to displacement.

\section{Literature Review}

One study to determine whether displacement occurs in a recreation setting was carried out by Dekker (1976). She looked primarily at private river runners' attitudes toward crowding on the Colorado River through Grand Canyon and Canyonlands National Parks, and attempted to relate these attitudes to behavioral intentions. One of her findings was that 25 percent of the users said the river was "too crowded" and they would not run it again if alternatives were available. This finding implies that potentially one-quarter of these users may be displaced in the future; that is, they may change their recreation behavior because of adverse conditions in the recreation setting.

Nielsen and Endo (1977) also attempted to link the concepts of crowding and displacement. They defined displacement as people leaving crowded areas for less crowded areas. In a study of experienced river runners they found that although crowding was a reason for changing areas, another reason was searching for more challenging rivers to run. Implicit in their findings is the notion that displacement is influenced by negative (crowding) as well as positive (challenging) factors. More recent studies have discounted this notion 
and have emphasized that displacement behavior is more likely influenced by the occurrence of negative factors alone.

Becker defined displacement as "a move away from an unacceptable situation rather than a move toward an optimal one" (Becker 1981, p. 262). In a 1977-1978 study, boaters on the Upper Mississippi and Lower St. Croix Rivers of Minnesota and Wisconsin were asked to respond to questions about use densities on both rivers. Perceived use densities, along with the boaters' evaluations of density, significantly affected changes users made on both rivers. That is, boaters who believed high use areas were unacceptable, moved from areas they perceived as high use to areas they perceived as low use. Specifically, boaters who believed use was heavier on the Lower St. Croix moved to the Upper Mississippi, and boaters who believed use was greater on the Upper Mississippi moved to the Lower St. Croix.

In the three studies mentioned, the presence of others appears to be an important cause for displacement. However, other factors must be considered if we are to build a holistic understanding of displacement. In a conceptual analysis of displacement, Schreyer (1979) broadened the meaning to include any change in the environment that users see as a threat to their satisfaction. Under his definition, essential components of the displacement process are a behavioral change, a time dimension, and changes in the environment. Also, he suggests that whether or not users are displaced depends on the users' characteristics. Although Schreyer did not collect and analyze data to empirically support his definition, at least two studies have incorporated some of his ideas. We review one of those studies here and report on the other one later in this paper.

Specialization, one user characteristic related to crowding, may also indicate displacement. In a study of Virginia canoeists, Roggenbuck et al. (1980) hypothesized that more specialized canoeists were more likely to be displaced from rivers than less specialized canoeists. They defined specialization as the user's level of involvement in river running, the amount of river running equipment owned, and the user's river running experience. Although their hypothesis was borne out, they caution that this finding is somewhat weak because only 13 percent of all canoeists gave crowding as a reason for avoiding some rivers.

\section{Conceptual Framework}

We have defined displacement as the outcome of a behavioral response to changes in the recreation environment. As such we have said that a link exists between user behavior and change in the environment. This link can be illustrated using Fishbein and Ajzen's (1975) model of behavioral intentions.

Their model of behavioral intentions can be presented as a series of hypotheses. In the first hypothesis:

$$
A_{B}=\sum_{i=1}^{n} b_{i} e_{i}
$$


where,

$A_{B}$ is an attitude toward performing a behavior.

$b$ is a belief about the consequences of performing a behavior.

e is an evaluation of the favorableness or unfavorableness. of performing a behavior.

Attitudes are comprised of a belief and an evaluation variable. Beliefs and evaluations in combination form the individual's attitude toward behavior. Thus, two people in the same environment may have different attitudes because their beliefs differ, their evaluations differ, or both their beliefs and evaluations differ.

In the second hypothesis:

$$
\mathrm{SN}=\sum_{\mathrm{i}=1}^{\mathrm{n}} \mathrm{b}_{\mathrm{i}} \mathrm{m}_{\mathrm{i}}
$$

where,

SN is the subjective norm or normative belief toward performing a behavior.

b is a belief, with respect to a relevant reference group, about performing a behavior.

$m$ is the motivation to comply with relevant reference groups.

Subjective norms are determined by an individual's expectations of relevant others and by the individual's motivation to comply with these expectations. As in the attitude example above, two people in the same environment may differ in their normative beliefs because their expectations of the beliefs of relevant others differ, their motivations to comply with relevant others differ, or both their expectations of beliefs and motivations to comply differ.

The third hypothesis combines the attitude and normative beliefs component and is

$$
\mathrm{B}-\mathrm{I}=\mathrm{A}_{\mathrm{B}} \mathrm{w}_{1}+\mathrm{SNw}_{2}
$$

where,

B is an overt behavior, and

I is intent to perform a behavior.

Behavioral intentions are determined by individual factors (attitudes) and social factors (norms). Intended behavior may or may not result in actual behavior. Behavioral intentions and actual behavior of people in the same environment may differ then, because they do not share the same attitudes and/or norms. 
In our study we examined user behavior and user attitudes toward selected outcomes in the recreation environment. Although we cannot show that a causal relationship exists between attitudes and displacement behavior, our interpretation of the data suggests that attitudes play a role in users' decisions to change. We did not measure the normative component. Fishbein and Ajzen (1975) have suggested that the normative component is the least understood of all the components and that the attitude component carries greater weight than the normative component in determining behavior.

Here is an example of the displacement process in recreation. Three hikers have traveled a particular trail in the past and are considering hiking it again. The first hiker believes that, unlike in the past, many other users are likely to be seen along the trail. This hiker does not like seeing lots of other users and therefore intends not to hike the trail again. We say this hiker has been displaced. The second hiker also believes more people will be using the trail than before but does not dislike seeing lots of others and intends to hike the trail again. The second hiker is not displaced. The third hiker decides not to use the trail again because it costs too much to drive to the trailhead. The hiker does believe more users will be on the trail, but this belief is irrelevant in this hiker's decision to use or not use the trail again. The change in behavior is not displacement because it is not made in response to a change in the recreation environment.

\section{The Boundary Waters Case}

For an initial look at our concept of displacement, we conducted a study in the Boundary Waters Canoe Area Wilderness of northeastern Minnesota to identify factors that might be related to displacement. The Boundary Waters encompasses more than one million acres of land and water, and it is the only lake-land wilderness area in the United States. It is managed by the USDA Forest Service.

\section{Methods}

Every group entering the Boundary Waters is required to have a permit and copies of the permits are retained by the supervisor's office of the Superior National Forest. We drew a sample of 1,016 names from permits issued between Memorial Day and Labor Day in 1978 and and in 1979. Each permittee included in the sample was sent a self-administered questionnaire. The initial mailing of questionnaires yielded a 47 percent response. After two follow-up mailings a total of 858 of the users surveyed (nearly 85 percent) had returned the questionnaire. No non-response check was made.

We recognized that users can be displaced from an area (i.e., leave an area and never return) as well as within an area (i.e., return to an area but use it differently). Because we were interested only in the displacement process within the Boundary Waters, we needed to look at people who had used the Boundary Waters several times. Therefore, we excluded people who had made fewer than five trips to the area from our study. After eliminating these people, 619 questionnaires remained. 
To construct the questionnaire, we conducted indepth interviews with 16 individuals. We interviewed university and Forest Service researchers who had extensive knowledge of the Boundary Waters and had used it frequently in the past. In addition, we selected names of several users from the 1979 summer use permits. We telephoned these users, told them about our study, and asked them how many years they had recreated in the Boundary Waters. We asked to interview those people who had recreated in the area 10 years or more. From these interviews, we identified 19 possible outcomes of use changes as potentially important to user displacement (Table 1). These outcomes were used in the mailback questionnaire to help us understand past and current user selection of entry points, campsites, and entry day. They were also used to assess user attitudes toward these specific behaviors.

We measured changes in behavior with the following questions:

a) On your recent visits to the Boundary Waters did you enter through different entry points than you did on your early visits?

b) On your recent visits to the Boundary Waters did you select campsites differently than you did on your early visits? and,

c) On your recent visits to the Boundary Waters did you enter on a different day of the week than you did on early visits?

We defined early visits as the first half of the total number of visits made to the Boundary Waters and recent visits as the last half of the total number of visits made. Respondents could answer either "yes, at least some of the time" or "no, never" to each question. For those answering yes, we measured their attitudes toward selected outcomes (Table 1) of the use changes. ${ }^{1}$

Beliefs about the outcomes of each use change were measured by asking respondents how likely each outcome would be had they not changed behavior. For example, those users who changed entry points were asked to:

Think back to your early visits to the Boundary Waters. Pick an entry point that you used on early visits but not on recent visits. Write the name of that entry point in the space provided. If you were to use that entry point now, how likely do you think each of the following would be?

Users who selected campsites differently or entered on a different day were asked similarly worded questions. A 7-point Likert scale, ranging from "not at all likely" (scale value $=0$ ) to "very likely" (scale value $=6$ ), was used to measure the strength of the users' beliefs about each outcome. Evaluations of outcomes were measured by asking users how much each outcome, associated with a use change, added to or detracted from the users' recreation experience. A 7-point Likert scale, ranging from strongly detracts (scale value $=-3$ ) to strongly adds (scale value $=+3$ ), was used to assess the strength of user eval-

'Attitude measurements were not made for those answering "no, never." 


\section{Outcomes Associated with Changing Entry Points, Campsites,} or Entry Days

\begin{tabular}{|c|c|c|c|}
\hline Outcomes & Entry Point & $\begin{array}{l}\text { Use Change } \\
\text { Campsite }\end{array}$ & Entry Day \\
\hline See litter along the shore $/$ & $\mathbf{x}$ & & \\
\hline See litter along portages . & $\mathbf{x}$ & & \\
\hline See worn-out campsites & $\mathbf{x}$ & & \\
\hline See worn-out portages & $\mathbf{x}$ & & \\
\hline See tents of others from my campsite & & $\mathbf{x}$ & \\
\hline Camp at sites close to hiking trails & & $\mathbf{x}$ & \\
\hline See watercraft pass by my campsite & & $\mathbf{x}$ & \\
\hline See peeled birch trees & & $\mathbf{x}$ & \\
\hline Find litter in the campsite area & & $\mathbf{x}$ & \\
\hline See canoes & $\mathbf{x}$ & & $\mathbf{x}$ \\
\hline See motorboats & $\mathbf{x}$ & & $\mathbf{x}$ \\
\hline Come into contact with noisy people & $\mathbf{x}$ & & $\mathbf{x}$ \\
\hline See other people at entry points & $\mathbf{x}$ & & $\mathbf{x}$ \\
\hline See other people on portages & $\mathbf{x}$ & & $\mathbf{x}$ \\
\hline \multicolumn{4}{|l|}{ See large groups (more than 5} \\
\hline people/group) & $\mathbf{X}$ & & $\mathbf{x}$ \\
\hline $\begin{array}{l}\text { See organizational groups (boy/girl scouts, } \\
\text { church, etc.) }\end{array}$ & $\mathbf{x}$ & & $\mathbf{x}$ \\
\hline Camp at heavily used campsites & & $\mathbf{x}$ & $\mathbf{x}$ \\
\hline \multicolumn{4}{|l|}{ Camp within hearing distance of others' } \\
\hline campsites & & $\mathbf{x}$ & $\mathbf{x}$ \\
\hline Camp within site of other campsites & & $\mathbf{x}$ & $\mathbf{x}$ \\
\hline
\end{tabular}

uations. Following the Fishbein formula for attitudes, belief scores and evaluation scores for each outcome were multiplied to develop attitude scores.

By our definition, displacement occurs when users change their behavior in response to perceived adverse changes in the recreation setting. Users perceptions of adverse social changes were identified through negative attitude scores. For example, a user may no longer use an entry point that was used frequently in the past because the user believes that if this entry point were used, contacts with noisy people would be "very likely." Moreover, these contacts "strongly detract" from the user's recreation experience. This user's belief score would be 6 and the evaluation score would be -3 , yielding an attitude score of -18 .

\section{Results}

\section{Behavior Changes}

We found that over time more than 70 percent of the respondents changed their use of the Boundary Waters. Eighty-four percent $(n=513)$ of 
these people used different entry points on recent trips compared to early trips. Seventy-five percent $(n=454)$ of the respondents selected campsites differently and 73 percent $(n=438)$ entered the Boundary Waters on a different day of the week.

\section{Beliefs and Evaluations of Beliefs}

Belief and evaluation scores are shown in Table 2 for outcomes associated with selecting entry points, campsites, and a day to enter the Boundary Waters. The scores were averaged across respondents. Belief scores greater than 3.00 are evidence that respondents believed the outcomes associated with one of the three changes were likely. Scores with values less than 3.00 indicate that outcomes associated with a behavior change were unlikely to occur. Evaluation scores greater than zero represent outcomes that are perceived as adding to the respondents' recreation experiences. And, outcomes perceived as detracting from experiences have score values of less than zero. None of the outcomes we report here added to the users' experiences.

Changes that respondents made in entry points and entry day show that respondents believed that if they behaved as in the past, then the outcomes listed were likely and would detract from their experiences. Means for outcomes related to campsite selection indicate that respondents believed that if early behaviors were followed most of these outcomes would be somewhat unlikely but any one of these outcomes would detract from their recreation experiences.

\section{Attitudes}

Using equation 1 , we combined belief and evaluation scores to determine respondents' attitudes with respect to each outcome (Table 3 ). Individual attitude scores for each outcome were averaged across respondents to produce aggregate attitude scores. To find out whether these attitude scores differed significantly from zero, we used the Z-test statistic:

$$
Z=\left(\overline{\mathbf{x}}_{\mathbf{i}}-\mathbf{M}_{\mathrm{o}}\right) /(\mathrm{s} / \sqrt{\mathbf{n}})
$$

where,

$\overline{\mathbf{x}}_{\mathrm{i}}$ is the population mean (in this case $\mathrm{M}_{\mathrm{o}}=0$ ),

$s$ is the standard deviation of the outcome, and

$\mathrm{n}$ is the number of people who responded.

The null hypothesis, $\bar{x}_{i}=M_{0}$, was rejected if $Z=-1.96$. For entry point outcomes $Z$ values ranged from -46.04 to -6.77 ; for campsite outcomes, they ranged from -35.32 to -5.50 ; and, for entry day they ranged from -40.30 to -5.98 . Consequently, the null hypothesis was rejected for each 
TABLE 2

\section{Belief and Evaluation Scores for Selected Outcomes}

\begin{tabular}{lcc}
\hline \hline & $\begin{array}{c}\text { Belief } \\
\text { Scores }\end{array}$ & $\begin{array}{c}\text { Eval. } \\
\text { Scores }\end{array}$ \\
\hline \multicolumn{1}{c}{ Outcomes Related to Changing Entry } & Points & \\
\hline See litter along portages & 4.04 & -2.70 \\
Come in contact with noisy people & 4.00 & -2.62 \\
See litter along the shore & 3.47 & -2.70 \\
See worn-out campsites & 4.14 & -2.08 \\
See large groups & 4.50 & -1.92 \\
See motorboats & 3.70 & -1.97 \\
See worn-out portages & 3.98 & -1.79 \\
See organizational groups & 4.34 & -1.59 \\
See other people at entry points & 5.20 & -1.17 \\
See people on portages & 4.74 & -1.18 \\
See canoes & 5.27 & -0.68 \\
\hline
\end{tabular}

\section{Outcomes Related to Changing Campsites}

$\begin{array}{lll}\text { Find litter in the campsite area } & 3.30 & -2.63 \\ \text { See peeled birch trees } & 3.16 & -2.62 \\ \text { Camp at heavily used campsites } & 2.73 & -2.12 \\ \text { Camp within hearing distance of others' campsites } & 2.25 & -2.34 \\ \text { Camp at sites easily seen from others' campsites } & 2.71 & -2.02 \\ \text { See tents of others from your campsite } & 2.82 & -1.98 \\ \text { See watercraft pass by my campsite } & 3.76 & -1.42 \\ \text { Camp close to hiking trails } & 1.78 & -1.02\end{array}$

Outcomes Related to Changing Entry Days

Come into contact with noisy people

Camp within hearing distance of others' campsites

See large groups

Camp at heavily used campsites

See motorboats

Camp at sites easily seen from others' campsites

See organizational groups

See other people at entry points

See other people on portages

See canoes

$\begin{array}{ll}4.04 & -2.64 \\ 3.71 & -2.32 \\ 4.33 & -1.91 \\ 3.83 & -2.11 \\ 3.86 & -1.96 \\ 3.82 & -1.93 \\ 4.40 & -1.57 \\ 4.84 & -1.18 \\ 4.66 & -1.15 \\ 5.00 & -0.73\end{array}$

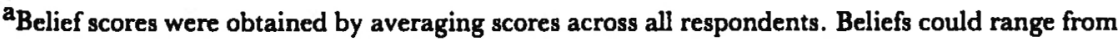
0.00 (not at all likely) to 6.00 (very likely).

${ }^{b}$ Evaluation scores were obtained by averaging scores across all respondents. Evaluations could range from -3.00 (strongly disagree) to +3.00 (strongly agree). 


\section{Mean Attitude Scores Toward Selected Outcomes}

\begin{tabular}{lcc}
\hline \hline & $N^{\mathbf{a}}$ & Score $^{\mathbf{b}}$ \\
\hline \multicolumn{1}{c}{ Outcomes Related to Changing Entry Points } \\
\hline See litter along portages & 484 & -11.05 \\
Come in contact with noisy people & 468 & -10.82 \\
See litter along the shore & 476 & -9.46 \\
See worn-out campsites & 427 & -9.43 \\
See large groups & 347 & -9.23 \\
See motorboats & 376 & -8.41 \\
See woin-out portages & 360 & -7.84 \\
See organizational groups & 310 & -7.12 \\
See other people at entry points & 247 & -6.34 \\
See people on portages & 292 & -5.90 \\
See canoes & 245 & -3.59 \\
\hline
\end{tabular}

\section{Outcomes Related to Changing Campsites}

Find litter in the campsite area

443

440

391

413

371

333

286

310
$-8.83$

$-8.30$

$-5.52$

$-5.17$

$-5.15$

$-4.95$

$-4.86$

$-1.43$

Camp close to hiking trails

Outcomes Related to Changing Entry Days

Come into contact with noisy people

Camp within hearing distance of others' campsites

See large groups

Camp at heavily used campsites

See motorboats

Camp at sites easily seen from others' campsites

See organizational groups

See other people at entry points

See other people on portages

See canoes

$\begin{array}{ll}389 & -10.88 \\ 370 & -8.75 \\ 291 & -8.73 \\ 350 & -8.29 \\ 302 & -8.01 \\ 333 & -7.51 \\ 258 & -7.40 \\ 198 & -5.89 \\ 237 & -5.65 \\ 193 & -3.77\end{array}$

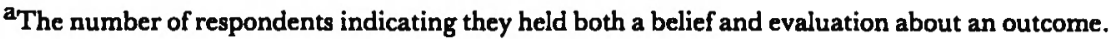

${ }^{b}$ Scores were obtained by multiplying belief scale values (range $=0$ to 6 ) by evaluation scale values (range $=-3$ to +3 ). 
attitude score - an indication that belief and evaluation scores related significantly to attitudes toward choosing previously selected entry points, campsites, and entry days.

Outcomes of litter, noise, and overuse (i.e., seeing worn-out campsites and portages, camping at heavily used sites) were perceived more negatively than outcomes associated with seeing other people. This finding was true for all three kinds of behavior changes we considered. We also found that compared to the number of users who perceived visual encounters with others as negative outcomes, there were more users who perceived litter, noise, and overuse as negative outcomes. The most striking implication of these findings is that displacement is likely to be caused by more than visual encounters with others. An additional implication is that encounters with others may not be as important to displacing users as other outcomes.

\section{Discussion}

Our findings must be interpreted with caution. Though we feel that outcomes identified are important in the displacement process, we hesitate to say that these outcomes are the major indicators of why people changed behaviors. We do not know the importance or effect of other factors such as lifestyle changes, knowledge of available alternatives, propensity to explore new areas, leisure time changes and discretionary income changes that might have played a role in the changes people made in their use patterns. Because other factors may weigh as heavily or more heavily in user decisions to alter use patterns, our findings about the number of users who changed behaviors only indicate the upper bound of displacement occurring within the Boundary Waters.

Our central purpose in this paper was to conceptualize the recreation displacement process. Other researchers have suggested that the process is linked to behavioral changes, time, and environmental changes perceived as threats to user satisfaction (Schreyer 1979; Roggenbuck et al. 1980). We investigated the process by relating perceived changes in a recreation environment to changes in specific user behaviors. To do this we represented displacement within the framework of the Fishbein-Ajzen model of behavioral intentions.

Our results appear to substantiate that the displacement process depends on the components described by Schreyer and others. Our results are consistent with the relations among concepts expressed in the Fishbein-Ajzen model, and we feel that it is a good model for further examination of the displacement phenomenon. A logical next study is a test of the correlations between behavior and possible determinants of displacement. From our data we cannot show that a causal relationship exists between outcomes, such as seeing litter and hearing noise, and behavior, such as changing entry points. At best our data are a partial test of the displacement process. High correlations would yield more conclusive support for using the Fishbein-Ajzen model in understanding the displacement process.

We also need to look at attitudes of users who do not change behaviors. Are their beliefs the same as users who change behaviors? Do they evaluate their beliefs in the same way? It may be that the same outcomes would be 
valued negatively but that they are not outcomes these users would experience. Are users who do not experience negative outcomes more successful in meeting their recreation expectations? Are their expectations different from users who are displaced? Parallel analysis of the attitudes and expectations of users who change behaviors with those of users who do not change behaviors would increase our understanding of the elements that make up the displacement process.

We found little support for crowding as an indicator of displacement in comparison to other possible indicators. One reason for such little support might be that crowding was defined by Dekker (1976), Roggenbuck et al. (1980), and Becker (1981) as "too many people in an area." The meaning of "too many" and "area" are ambiguous, thereby increasing the probability of measurement error (Nunnally 1967). In our study we measured users' responses to several potential outcomes of recreating in the Boundary Waters that we believed tapped different aspects of crowding - seeing large groups, seeing organizational groups, seeing other people at entry points, and seeing people on portages. Other outcomes, though less specific, probably are related to a feeling of crowding - seeing litter along portages, in campsites, and at entry points; seeing evidence of overuse at entry points, portages, and campsites; and coming into contact with noisy people. Support for the occurrence of displacement in earlier studies might have been greater if crowding had been defined in a less general way. Confusion about the role of crowding in the displacement process points to a need for better definitions and measures of crowding in future studies.

Our study findings are also relevant to management of the Boundary Waters. The outcomes we identified as related to displacement can be managerially controlled or manipulated. Our study documents that change is taking place within the Boundary Waters and that this change is at least partly due to adverse social conditions. Being aware of the conditions and the resulting changes in use patterns is useful in planning efforts and can lead to specific management objectives and practices. For example, during 1983 Boundary Waters resource administrators will develop a new multi-year management plan for the area: Their management strategy will be based on guidelines outlined in the Recreation Opportunity Spectrum (ROS) system. For management purposes the Boundary Waters has been divided into three of the six zones included under ROS: primitive, semi-primitive nonmotorized, and semi-primitive motorized. Managers are charged with providing different kinds and levels of recreation opportunities for each zone. Information from our study about resource conditions that might influence displacement is one input these administrators will use as they develop carrying capacities for these zones (Sober 1983). For example, campsites might be spaced a greater distance apart in primitive zones than in semi-primitive zones. This action, while controlling for the total number of users allowed in primitive zones, would also decrease the chance of hearing or seeing other users from a campsite. Although the study data have limitations, we are encouraged by the response of these resource administrators and what we might learn as they implement new management actions in the Boundary Waters. 


\section{References}

Ajzen, I. and Fishbein, M. 1980. Understanding attitudes and predicting sacial behavior. Englewood Cliffs, N.J.: Prentice-Hall. 278 p.

Anderson, D. H. 1980. Displacement of visitors within the Boundary Waters Canoe Area Wilderness. Unpublished Ph.D. dissertation, Dept. of Recr. Resour., Colorado State University, Ft. Collins, CO. 130 p.

Becker, R. H. 1981. Displacement of recreational users between the Lower St. Croix and Upper Mississippi Rivers. Journal of Environmental Management 13(3):259-267.

Bell, P. A., Fisher, J. D., and Loomis, R. J. 1978. Environmental psychology. Philadelphia, Pa.: W. B. Saunders Co.

Cohen, J. L., Sladen, B., and Bennett, B. 1975. The effects of situational variables on judgments of crowding. Sociometry 38:273-281.

Dekker, E. A. 1976. Private use of the Colorado River in the Grand Canyon and Canyonlands National Parks. Unpublished USDI Interim Report. National Park Service, Grand Canyon, AZ.

Driver, B. L. and Bassett, J. 1975. Defining conflicts among river users. Naturalist 26(2):19-23.

Fishbein, M. and Ajzen, I. 1975. Belief, attitude, intention, and behavior: an introduction to theory and research. Reading, Mass.: Addison-Wesley Publ. Co. 578 p.

Janeksela, G. M. 1978. Predicting behavior from attitudes: problems and solutions. International Review of Modern Sociology 8:245-256.

Langer, E. and Saegert, S. 1977. Crowding and cognitive control. Journal of Personality and Social Psychology 35:175-182.

Miniard, P. W. and Cohen, J. B. 1981. An examination of the Fishbein-Ajzen behavioral intentions model's concepts and measures. Journal of Experimental Social Psychology 17:309-339.

Nielsen, J. M. and Endo, R. 1977. Where have all the purists gone? an empirical examination of the displacement hypothesis in wilderness recreation. Western Sociological Review 8(1):61-75.

Nunnally, J. C. 1967. Psychometric theory. New York, N.Y.: McGraw-Hill Book Co. 640 p.

Roggenbuck, J. W., Wellman, J. D., and Smith, A. C. 1980. Specialization, displacement, and definition of depreciative behavior among Virginia canoeists. Final Report, Dept. of Forestry, VPI and State University, Blacksburg, Va. 109 p.

Schreyer, R. 1979. Succession and displacement in river recreation. Part 1, problem definition and analysis. Unpublished report, Dept. of Forestry and Outdoor Recreation, Utah State University, Logan, Utah.

Smith, A. C., Wellman, J. D., Roggenbuck, J., and Killeen, K. In press. Priorities for river recreation management in the Southern Appalachians. Southem Journal of Applied Forestry.

Sober, T. 1983. Personal communication with Mr. Sober, Boundary Waters administrator, about establishing carrying capacity limits in the Boundary Waters.

Stokols, D. 1972a. On the distinction between density and crowding: some implications for future research. Psychological Review 79(3):275-278.

Stokols, D. 1972b. A social psychological model of human crowding phenomena. American Institute of Planners Joumal. 38:72-83.

Washburne, R. F. 1981. Carrying capacity assessment and recreational use in the national wilderness preservation system. Journal of Soil and Water Conservation 36(3):162-166.

Wicker, A. W. 1969. Attitude versus actions: the relationship of verbal and overt behavioral responses to attitude objects. Journal of Social Issues 25(4):41-78.

Willis, M. P., Shontz, W. D., Dorfman, P. W., and Williams, A. I. 1978. Recreation lifestyle versus activity involvement patterns: beliefs as correlates of behavior. Psychological Reports 43:1219-1229.

Zimbardo, P. G., Ebbesen, E. B., and Maslach, C. 1977. Influencing altitudes and changing behavior: an introduction to method, theory, and applications of social control and personal-power. 2nd edition. Reading, Mass.: Addison-Wesley Publ. Co. 271 p. 